\title{
CONHECIMENTO TEÓRICO E PERCEPÇÃO DE ACADÊMICOS DE PSICOLOGIA SOBRE DISLEXIA
}

\author{
PSYCHOLOGY ACADEMICS' THEORICAL KNOWLEDGE AND PERCEPTION OF \\ DYSLEXIA
}

\section{CONOCIMIENTO TEÓRICO Y PERCEPCIÓN DE ESTUDIANTES DE PSICOLOGÍA SOBRE LA DISLEXIA}

\author{
SCHÜNKE, Lumachelle Laiz \\ luma.Ihaiz@gmail.com \\ Univinci Uniasselvi \\ https://orcid.org/0000-0003-1611-2368 \\ BORBA, Jesiane \\ jesyanne_borba@hotmail.com \\ Univinci Uniasselvi \\ https://orcid.org/0000-0001-5902-8268 \\ GLIDDEN, Rosina Forteski \\ rsforteski@gmail.com \\ Univinci Uniasselvi \\ https://orcid.org/0000-0003-1521-8240
}

RESUMO A dislexia é um transtorno específico de aprendizagem que compromete as áreas da leitura, escrita e soletração. Esta pesquisa teve por objetivo analisar a percepção e o conhecimento sobre aspectos relacionados à dislexia em acadêmicos de Psicologia de uma faculdade do norte de Santa Catarina. Participaram 55 acadêmicos de Psicologia. Foi aplicado um questionário semiestruturado e gerados os testes Qui Quadrado e $t$ de Student e medidas descritivas. As respostas às perguntas abertas foram categorizadas por semelhança semântica. Os resultados mostraram diferença significativa na percepção entre os semestres referente à capacidade de identificar e diagnosticar uma pessoa com dislexia, porém, não houve diferença no conhecimento sobre o transtorno. Conclui-se pela importância de discutir o tema com mais ênfase no curso de Psicologia.

Palavras-chave: Aprendizagem. Dislexia. Psicologia.

ABSTRACT Dyslexia is a specific learning disorder that compromises the areas of reading, writing, and spelling. This research aimed to analyze the perception and knowledge of Psychology academics from a college in northern Santa Catarina on aspects related to dyslexia. Fifty-five psychology students participated in the study. A semi-structured questionnaire was applied, and the analyses were generated through descriptive measures and the Chi-Square and Student $t$ tests. The answers to the qualitative questions were categorized by semantic similarity. The results showed a 
significant difference in the students' perception between the initial and final semesters regarding their ability to identify and diagnose a person with dyslexia. However, there was no significant difference regarding their knowledge of dyslexia. In conclusion, it is important to discuss the subject with more emphasis within a Psychology course.

Keywords: Dyslexia. Learning. Psychology.

RESUMEN La dislexia es un trastorno de aprendizaje específico que compromete la lectura, la escritura y la ortografía. Esta investigación tuvo como objetivo analizar la percepción y el conocimiento sobre aspectos relacionados con la dislexia en estudiantes de psicología de una universidad del norte de Santa Catarina. Participaron 55 estudiantes de psicología. Se aplicó un cuestionario semiestructurado y las pruebas t de Chi-cuadrado y de Student y medidas descriptivas fueron generados. Las respuestas a las preguntas abiertas se clasificaron por similitud semántica. Los resultados mostraron diferencias significativas en la percepción entre semestres con respecto a la capacidad de identificar y diagnosticar a una persona con dislexia, pero no hubo diferencias en el conocimiento sobre el trastorno. Se concluye por la importancia de discutir el tema con más énfasis en el curso de Psicología.

Palabras-clave: aprendizaje. Dislexia. Psicologia.

\section{INTRODUÇÃO}

A Classificação Internacional de Doenças - CID 10 (OMS, 1993), em sua décima revisão, reconhece a dislexia como um transtorno específico de leitura, no qual o processo de aprendizagem se vê alterado desde o início das fases do desenvolvimento. O Manual Diagnóstico e Estatístico de Transtornos Mentais - DSM5 (APA, 2014) inclui a dislexia nos Transtornos Específicos de Aprendizagem e a descreve como uma perturbação da leitura e da escrita. Trata-se de uma condição hereditária da linguagem, com alterações genéticas e de origem neurobiológica $(A B D$, 2016).

Sendo a dislexia um transtorno neurológico e crônico, entende-se que não há cura, e sim uma adaptação do indivíduo para uma convivência melhor com os sintomas. Sobre as possíveis causas da dislexia, nota-se que há, entre estudiosos da temática, uma relativa concordância sobre ela ocorrer em função de um déficit fonológico. Os sintomas tendem a aparecer e ser identificados nos anos iniciais da infância, na fase de alfabetização, quando o aluno apresenta dificuldade de acompanhar o andamento da aula, principalmente nas atividades de leitura e escrita (CABUSSÚ, 2009). 
Atualmente a dislexia é um sério desafio a ser enfrentado pela sociedade, principalmente no contexto educacional, por ser uma dificuldade de aprendizagem na leitura, escrita e soletração, e que envolve também problemas com a linguagem expressiva, receptiva, social e corporal e cálculos matemáticos (FERREIRA, 2011). Entretanto, embora os disléxicos apresentem estas características, eles podem mostrar desenvolvimento superior em outras áreas como a esportiva, a musical e a criativa (INSTITUTO DE APOIO À CRIANÇA, 2011; SOUZA, 2011). Um disléxico pode, inclusive, apresentar superdotação (TAUCEI; STOLTZ; GABARDO, 2013).

A avaliação psicológica do transtorno deve ser realizada considerando-se aspectos emocionais, perceptuais e intelectuais da pessoa (ANDRADA, 2005), ela permite identificar as dificuldades apresentadas pelo aluno, para que os profissionais envolvidos tomem medidas primordiais para a sua inclusão e realizem uma programação educacional individual que atenda às suas necessidades específicas de aprendizagem. Esse processo também permite ao professor, pelos erros apresentados pelo aluno, verificar o domínio ortográfico e investigar suas dificuldades particulares (RODRIGUES, 2012).

Existem alguns aspectos que precisam ser considerados para diagnosticar a dislexia como, por exemplo, se existe ocorrência em pessoas da família, se é apresentada dificuldade para ler, escrever e soletrar, pânico ao ler em voz alta, ansiedade ao realizar testes, dificuldades ortográficas, entre outros (DEUSCHLE; CECHELLA, 2009). Souza (2011) também propõe que algumas informações são de essencial relevância para o diagnóstico, como o desenvolvimento da criança, histórico familiar, desempenho escolar e métodos de ensino/aprendizagem. Sendo assim, os pais e a escola são fontes essenciais de informação. A finalidade não é rotular, mas realizar um prognóstico para prestar auxílio eficaz ao aluno.

O diagnóstico da dislexia deve ser feito por uma equipe multidisciplinar para que um acompanhamento efetivo seja realizado, respeitando a singularidade de cada pessoa na busca de resultados mais precisos (SILVA, 2009). É de grande importância o diagnóstico precoce para suavizar o impacto do transtorno da dislexia, quanto mais cedo ela for diagnosticada, antes pode ser tratada, o que contribuiria para o aprimoramento das condições de aprendizagem da criança (CARVALHAIS; SILVA, 2007; RODRIGUES; CIASCA, 2016). 
A intervenção tardia é mais difícil por questões relacionadas ao funcionamento e à maturidade cerebral e também porque comorbidades psicológicas ou psiquiátricas podem associar-se à dislexia com o passar dos anos. Na adolescência é comum que o jovem com dislexia alcance os anos finais do ensino fundamental com hipóteses diagnósticas diversas, que vão desde transtornos psiquiátricos, até problemáticas intrínsecas a ele ou a sua família. Neste segundo caso, fatores como desmotivação, problemas de ordem emocional, falta de empenho e problemas da família são tomados como causa das dificuldades apresentadas pelo adolescente (RODRIGUES; CIASCA, 2016). Esse cenário desnuda uma trajetória excludente que pode colaborar efetivamente para o fracasso e para a evasão escolar.

A dislexia é talvez o motivo mais constante de baixo rendimento e fracasso escolar e, na grande maioria dos casos, ela não é identificada, nem devidamente tratada (TELES, 2004). Porém, ela não tem sua gênese em má alfabetização, distração, falta de interesse ou baixa inteligência (ASSUNÇÃO, 2018; PIMENTA, 2012). Neste sentido, Cabussú (2009) alerta que o ambiente escolar pode ser um dos maiores estressores da criança com dislexia, pois nele ela convive com outras crianças que não apresentam as mesmas dificuldades de leitura e escrita.

Quanto às prováveis consequências da dislexia no decorrer da vida do sujeito, pode-se citar: baixo rendimento na área acadêmica, maiores chances de evasão escolar, diminuição nos índices de educação superior, elevados índices de desemprego e renda baixa na vida adulta. Também podem ocorrer altos níveis de sofrimento psicológico e sinais de depressão e saúde mental em pior estado de forma geral (APA, 2014). Ainda, pesquisas apontam que a dislexia traz consequências emocionais negativas, como vergonha, insegurança, frustração (MANGAS; SÁNCHEZ, 2010), baixa autoestima (BONINI et al., 2010; VÁZQUEZ et al., 2017), agressividade, ansiedade, depressão (BONINI et al., 2010; SAKO, 2016), estresse (CABUSSÚ, 2009), sentimentos de inferioridade (STERN, 2010) e dificuldades acadêmicas (BONINI et al., 2010; MANGAS; SÁNCHEZ, 2010; STERN, 2010; VÁZQUEZ et al., 2017), além maiores chances de vitimização por bullying (STERN, 2010).

Os aspectos emocionais e os estressores vivenciados pelos disléxicos nos diversos ambientes em que circulam, segundo Cabussú (2009), necessitam de uma 
atenção maior dos pesquisadores. Sako (2016) chama também a atenção para os aspectos emocionais da dislexia, salientando que eles são, com frequência, subestimados. Para a autora, a frustração frente ao desencontro que ocorre entre as expectativas das pessoas e desempenho real da criança com dislexia acaba por levar a um sentimento crescente de inadequação. Essa noção de inadequação pode, a longo prazo, causar muitos problemas em sua vida pessoal e social.

Relacionada a questões como baixa autoestima, insegurança e inadequação está a autoeficácia. Este conceito descreve a crença que a pessoa desenvolve sobre sua capacidade de realizar determinadas ações. Neste sentido, Stagg, Eaton e Sjoblom (2018) realizaram uma pesquisa explorando as crenças de autoeficácia de estudantes universitários com e sem dislexia. Os estudantes com dislexia obtiveram menores escores que os estudantes sem dislexia em quatro das cinco medidas de autoeficácia acadêmica. Os estudantes disléxicos relataram modelos, professores e desempenho escolar como fatores que influenciavam sua motivação para o trabalho acadêmico. Para os autores, os resultados da pesquisa sugerem que, apesar de o nível de sucesso alcançado na obtenção de um lugar na universidade, os estudantes universitários com dislexia ainda precisam de intervenções que os ajudem a aumentar suas crenças de autoeficácia.

Vázquez et al (2017) realizaram uma pesquisa sobre as consequências da dislexia, discalculia e disgrafia na educação equatoriana por meio de revisão de literatura. Os achados mostraram que os alunos que apresentam estes transtornos são tratados como incapazes e mal-educados e, ainda, que há culpabilização dos pais pelo desempenho insuficiente de seus filhos. Os autores concluíram que a desmotivação em relação aos estudos acadêmicos, a baixa autoestima e a evasão escolar são as consequências mais visíveis em todos os níveis de ensino, demandando assim intervenções adequadas e imediatas, pautadas em conhecimento científico.

A dislexia deve ser identificada no processo educacional, pois a criança com o transtorno necessita de apoio profissional e emocional dos pais, professores e demais profissionais, a fim de continuar sua vida escolar sem que ele seja um empecilho para o seu desenvolvimento (SOUZA, 2011). Nesse sentido, de acordo com Rodrigues (2012), para que o objetivo de continuidade adequada da vida escolar do aluno seja 
alcançado, o professor deve encaminhá-lo para serviços especializados, como de Psicologia ou outros Serviços de Saúde, onde serão aplicados instrumentos para diagnosticar possíveis dificuldades na leitura e na escrita, dentre outras ações.

Diante da importância da Psicologia nesse contexto, vista como referência para avaliar e diagnosticar os problemas de aprendizagem, se estabelece a relevância acadêmica e social de estudar o transtorno de acordo com a percepção e o conhecimento de futuros psicólogos. Para tanto, foi objetivo desta pesquisa investigar a percepção e o conhecimento de acadêmicos de Psicologia de uma faculdade do Norte de Santa Catarina sobre aspectos relacionados à dislexia.

\section{MITOS RELACIONADOS À DISLEXIA}

As competências cognitivas superiores, fundamentais para o entendimento e aprendizagem da criança, estão intactas em uma criança com dislexia, como a sua inteligência geral, vocabulário, construção de opiniões, argumentação e raciocínio (TELES, 2004). Portanto, a dislexia não está relacionada à baixa inteligência do indivíduo (ASSUNÇÃO, 2018; INSTITUTO DE APOIO À CRIANÇA, 2011; PIMENTA, 2012). As crianças com dislexia podem apresentar uma capacidade intelectual superior à média em atividades que não dependam propriamente da leitura e da escrita (INSTITUTO DE APOIO À CRIANÇA, 2011). Teles (2004) relata que até pouco tempo a dislexia era entendida como uma incapacidade sem origem orgânica. A falta de conhecimento científico das pessoas colaborou para o surgimento de vários mitos relacionados ao transtorno, como os elencados a seguir:

$1^{\circ}$ Mito: Crença de que não existem meios para diagnosticar a dislexia, porém, atualmente existem saberes que possibilitam a avaliação e o diagnóstico de pessoas disléxicas, inclusive com testes específicos para a avaliação de suas competências.

$2^{\circ}$ Mito: Crença de que a dislexia só pode ser diagnosticada e tratada quando primeiro ocorre o insucesso escolar. As dificuldades de aprendizagem podem e devem ser diagnosticadas o mais cedo possível e conhecer o transtorno possibilita identificar sinais de alerta, como o comprometimento na aprendizagem da linguagem oral.

$3^{\circ}$ Mito: Crença de que a dislexia pode passar com o tempo, mas ela permanece na vida adulta. 
$4^{\circ}$ Mito: Pensar que repetir o ano pode auxiliar na superação das dificuldades. Porém, a repetência pode produzir ainda mais problemas para o aluno, relacionadas a questões afetivas e emocionais.

$5^{\circ}$ Mito: Crença de que a dislexia é um problema visual, quando o que ocorre é a inversão de letras, vistas ao contrário por terem o mesmo ponto de conexão.

$6^{\circ}$ Mito: Acreditar que a dislexia pode ser causada por dificuldades de orientação espacial, contudo, as dificuldades espaciais são independentes da dislexia.

$7^{\circ}$ Mito: Crença de que a dislexia existe apenas em algumas línguas. A dislexia se manifesta em todas as línguas, porém, em algumas é possível se cometer mais erros que em outras, decorrentes das diferentes ortografias.

$8^{\circ}$ Mito: Acreditar que é melhor evitar diagnosticar crianças disléxicas, pois o rótulo contribuiria para agravar a dislexia. Entretanto, ignorar um distúrbio contribui para o seu agravamento.

O desconhecimento das causas da dislexia até pouco tempo auxiliou no aparecimento de teorias explicativas falsas e, como resultado, intervenções terapêuticas sem nenhuma validação científica. Surgiram terapias com base em interpretações psicológicas desvinculadas das atividades biológicas e terapias baseadas em déficits perceptivos, psicomotores ou visuais (TELES, 2004).

Quando a dislexia é cercada de mitos, os critérios usados para caracterizá-la são, em grande parte, do senso comum. Assim, se os conceitos traduzem fatos científicos, as ações para superar o transtorno podem não ser confiáveis. Neste sentido, os trabalhos realizados com alunos disléxicos nestas situações não teriam eficácia (VERAS, 2013). Daí se pode estabelecer a importância de os profissionais conhecerem melhor o transtorno, o que os educaria na escolha dos procedimentos e técnicas necessários na abordagem de tratamento.

A pesquisa de Pimenta (2012) teve como objetivo caracterizar a percepção de professores sobre dislexia. Foi aplicado um questionário com 20 professoras de escolas públicas em uma cidade de Minas Gerais com questões sobre o que é a dislexia e como elas lidavam com a dislexia em sala de aula. Os resultados mostraram que todas as professoras afirmaram saber o que é dislexia, $75 \%$ já haviam lidado com alguma criança com dislexia ou com indícios do transtorno e $25 \%$ afirmaram nunca 
terem lidado com o transtorno. Ainda, 60\% não relacionaram dislexia com inteligência. Porém, a autora concluiu que, embora as professoras tivessem conhecimento sobre a dislexia, estavam despreparadas para lidar com o transtorno em sala, por falta de oportunidade, tempo ou mesmo interesse no assunto.

O trabalho de Pereira et al (2011) teve como objetivo investigar o conhecimento prático-teórico sobre a dislexia do desenvolvimento em educadores nas redes pública e privada de ensino. Foi aplicado um questionário com 103 professores de 14 escolas. Os resultados identificaram que 64\% cursaram alguma disciplina relacionada ao assunto, 59\% buscaram formação extracurricular sobre o tema, 50\% souberam conceituar a dislexia e $98 \%$ identificaram corretamente suas causas. A maioria dos educadores apresentou algum conhecimento referente à dislexia, o que permitiria que eles identificassem corretamente o conceito, suas principais características e causas, e que pudessem reconhecer quais profissionais podem ser envolvidos no processo de tratamento.

A Psicologia serve como referência para avaliar e diagnosticar os problemas de aprendizagem da leitura, contribuindo com estratégias de intervenção eficientes. No processo de intervenção de uma pessoa com dislexia o profissional deve considerar alguns aspectos como: fatores ambientais do contexto em que o aluno está inserido, se o sistema de ensino condiz com as necessidades educativas do educando e o contexto familiar e sua interação com as dificuldades específicas de aprendizagem da leitura. Os papéis da escola e da família são essenciais na identificação precoce das adversidades, inclusive no processo de tratá-las e superá-las (SALLES; PARENTE; MACHADO, 2004).

\section{MÉTODO}

\subsection{CARACTERIZAÇÃO DA PESQUISA}

Este é um estudo descritivo, exploratório e relacional, de delineamento misto, quali e quantitativo.

\subsection{AMOSTRA}


Foi utilizada uma amostra de conveniência, composta por 55 acadêmicos do curso de Psicologia, com idade igual ou superior a 18 anos, de uma faculdade do Norte de Santa Catarina. A pesquisa foi aprovada por um Comitê de Ética em Pesquisa - CEP PLATAFORMA BRASIL, com o Parecer $n^{\circ} 1.698 .036$, e atende aos fundamentos éticos e científicos pertinentes à Resolução do CONEP n 466 de 2012, pelo Conselho Nacional de Saúde (CNS), para pesquisas com seres humanos, publicada em 13 de junho de 2013 no Diário Oficial da União. A pesquisa utilizou-se do Termo de Consentimento Livre e Esclarecido (TCLE), que foi assinado em duas vias de igual teor, ficando uma com o participante e outra com as pesquisadoras.

\subsection{INSTRUMENTO DE COLETA DE DADOS}

Foi utilizado um questionário semiestruturado composto por oito questões sociodemográficas, duas questões abertas e 18 questões fechadas que abordavam os temas centrais da pesquisa, construídas em conjunto pelas pesquisadoras com base na literatura sobre o tema. Dez questões compunham o teste de conhecimento sobre dislexia, destas, uma se tratava da definição; uma, da origem do transtorno e as outras oito eram sobre crenças e mitos relacionados à dislexia relatados por Teles (2004).

No teste de conhecimento os itens apresentados por Teles (2004) foram transformados em afirmativas. Os itens de resposta consistiam em verdadeiro ou falso. Apenas a primeira questão do teste sobre conhecimento possuía quatro opções de resposta. Esta pergunta abordava a descrição do conceito de dislexia e, para a construção desta pergunta, foi tomado como base o que aponta o DSM 5 (APA, 2014) sobre o transtorno.

\section{ANÁLISE E INTERPRETAÇÃO DOS RESULTADOS}

Nas análises foram geradas medidas descritivas e os testes estatísticos Qui Quadrado e $t$ de Student. A comparação entre grupos (semestres iniciantes e semestres concluintes) foi feita utilizando-se o Test $t$ de Student. Dispensou-se o teste de Normalidade com base nas recomendações de Pestana e Gageiro (2003), que sustentam que, no caso de amostras com mais de 30 participantes, não é necessário 
realizá-lo. As respostas às perguntas abertas foram categorizadas por semelhança semântica.

\subsection{CARACTERIZAÇÃO DOS PARTICIPANTES}

Para fins de comparação os semestres foram agrupados em iniciantes e concluintes, sendo os iniciantes o $1^{\circ}$ e o $2^{\circ}$ e os concluintes, o $9^{\circ}$ e o $10^{\circ}$ semestres. Dos participantes $(n=55), 61,8 \%$ eram dos semestres iniciantes e $38,2 \%$, dos concluintes. Com relação ao sexo, $81,8 \%$ dos participantes eram do feminino, a idade média foi de 23,8 anos, com desvio padrão de 6,25 . Ainda, $76,4 \%$ eram solteiros, $21,8 \%$ eram casados ou moravam junto e $1,8 \%$, divorciados. Não tinham filhos $87,3 \%$, $70,9 \%$ estavam trabalhando e $94,3 \%$ não possuíam outra graduação completa.

\subsection{CONTATO COM O TEMA DISLEXIA}

Foi perguntado aos participantes se eles conheciam alguém que tivesse dislexia, apenas $10,9 \%(n=5)$ relataram conhecer. Dos que relataram conhecer, três conheciam uma criança ou adolescente e dois, um adulto. Quanto a terem tido algum contato anterior à faculdade com o tema dislexia, 50,9\% afirmaram que já haviam tido contato. Sobre os tipos de contato, obtiveram-se os seguintes dados apresentados na Figura 1.

Figura 1: Tipos de contato que os participantes tiveram com o tema dislexia anteriormente à faculdade 


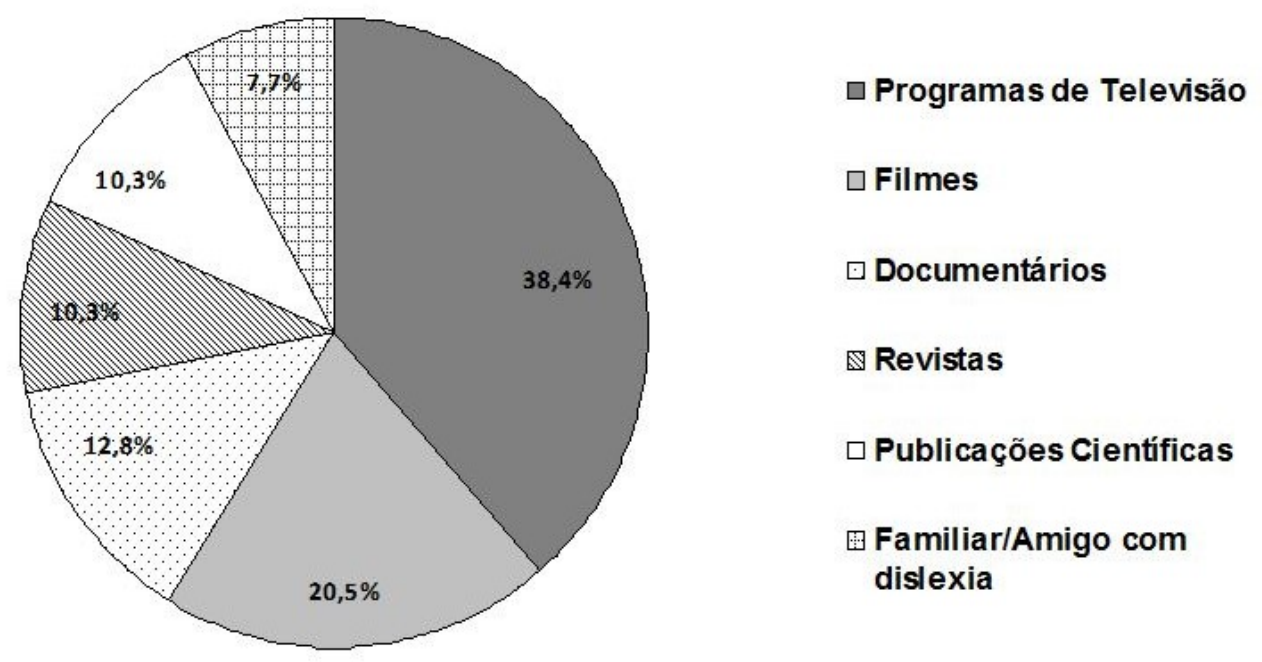

Fonte: dados da própria pesquisa.

Observa-se na Figura 1 que a maioria $(38,4 \%)$ teve contato com o tema por meio de "programas de televisão", seguidos de "filmes" (20,5\%) e "documentários" $(12,8 \%)$. A categoria com menos menções foi "familiar/amigo com dislexia", com 7,7\%, sendo este um dado coerente com o resultado que diz que somente $10,9 \%(n=5)$ dos participantes relataram conhecer alguém com dislexia.

Pode-se perceber ainda que a categoria "publicações científicas" aparece com apenas $10,3 \%$ de menções, o que pode se relacionar ao fato de que a questão se refere ao contato anterior à faculdade e, geralmente, as pessoas começam a ler artigos científicos após iniciarem um curso superior. $O$ dado que aponta a televisão como fonte mais citada revela a extensão do poder deste veículo de comunicação, que pode tanto ajudar a desmistificar e conscientizar sobre o tema, como a fortalecer estereótipos e mitos a seu respeito.

Veras (2013) relata que a dislexia é permeada de mitos e, muitas vezes, os critérios usados na sua caracterização originam-se do senso comum. Teles (2004) complementa que a falta de conhecimento científico das pessoas está relacionada ao surgimento de vários mitos relacionados ao transtorno. Portanto, pode-se ressaltar a importância de pautar o conhecimento sobre o tema dislexia na ciência, para evitar o surgimento de teorias falsas sobre a temática. 


\subsection{FREQUÊNCIA COM QUE O TEMA DISLEXIA FOI ABORDADO EM SALA}

Foi encontrada uma significância $\left(\chi^{2}=6,36 ; p<0,05\right)$ na relação entre a frequência com que o tema dislexia foi abordado em sala entre os semestres iniciantes e concluintes, como pode ser observado na Tabela 1, a seguir:

Tabela 1: Relação entre os semestres iniciantes e concluintes sobre a frequência com que o tema dislexia foi abordado em sala $\left(\chi^{2}=6,36 ; p<0,05\right)$

\begin{tabular}{lcc}
\hline Níveis & Iniciantes (\%) & Concluintes (\%) \\
\hline Algumas vezes & $26,5 \%$ & $35,0 \%$ \\
Poucas vezes & $47,0 \%$ & $65,0 \%$ \\
Nenhuma vez & $26,5 \%$ & $0,0 \%$ \\
Muitas vezes & $0,0 \%$ & $0,0 \%$ \\
\hline Total & $100,0 \%$ & $100,0 \%$ \\
\hline
\end{tabular}

Fonte: dados da própria pesquisa.

Observa-se na Tabela 1 que apenas alunos iniciantes (26,5\%) relataram que o tema dislexia não tinha sido abordado "nenhuma vez" em sala e uma porcentagem maior de alunos dos concluintes $(35,0 \%)$ apontou que o tema havia sido abordado "algumas vezes". Pode-se pontuar ainda que não houve opção de nenhum semestre pelo item de resposta "muitas vezes". Porém, em comparação, os concluintes relataram terem tido mais contato com o tema em sala de aula.

\subsection{PERCEPÇÃO SOBRE A CAPACIDADE DE IDENTIFICAR E DIAGNOSTICAR A DISLEXIA}

Foi perguntado aos participantes se eles se sentiam capacitados para identificar e diagnosticar a dislexia. Em ambos os casos, houve relação significativa quando consideradas as diferentes fases de formação. Sobre a percepção acerca da capacidade de identificar uma pessoa com dislexia, cruzada com a variável fase de formação, os dados da relação significante $\left(\chi^{2}=8,65 ; p<0,05\right)$ podem ser observados na Figura 2, a seguir:

Figura 2: Relação referente à percepção dos alunos iniciantes e concluintes sobre a sua capacidade de identificar uma pessoa com dislexia $\left(\chi^{2}=8,65 ; p<0,05\right)$ 


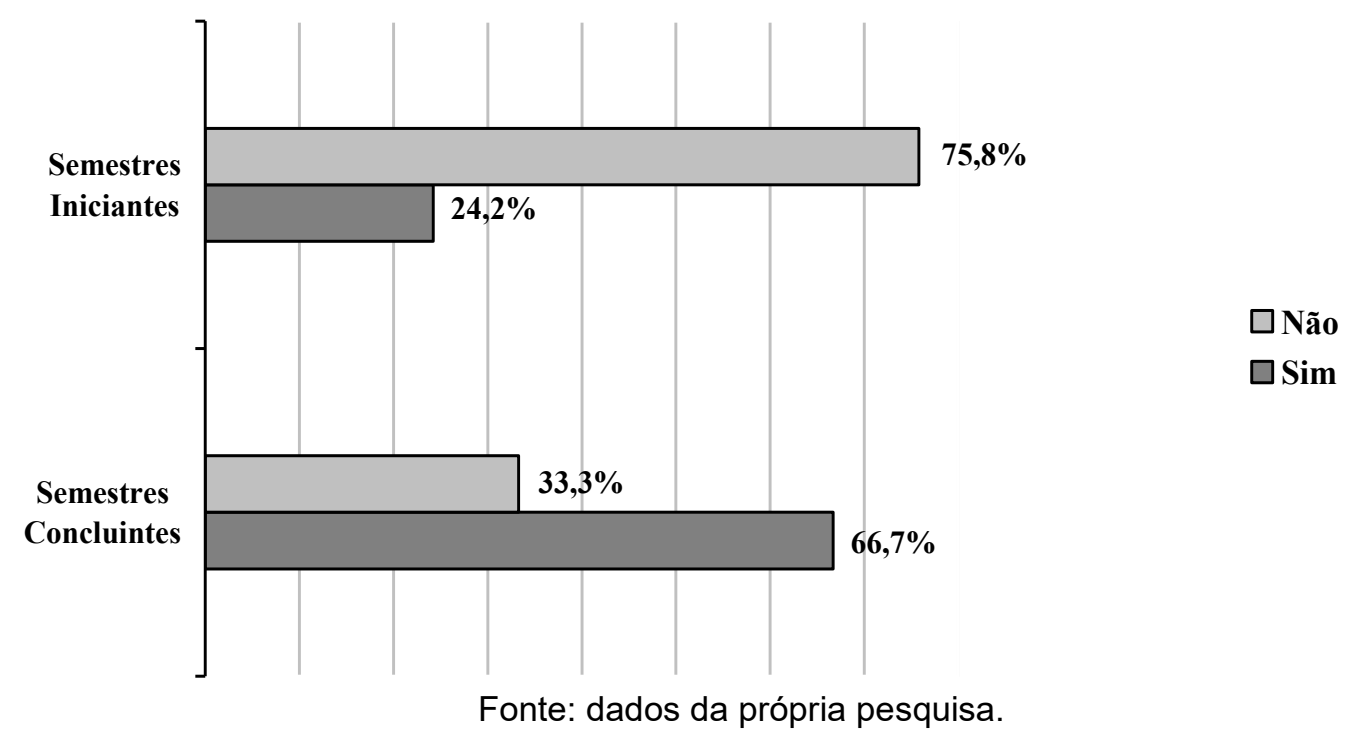

Observa-se na Figura 2 que a maioria dos alunos iniciantes $(75,8 \%)$ relatou que não se considerava capacitada a identificar uma pessoa com dislexia, entre os alunos concluintes $33,3 \%$ não se consideravam capacitados. Ou seja, em comparação, os alunos dos semestres concluintes se percebiam mais capacitados a identificar uma pessoa com dislexia.

A identificação da criança disléxica é importante, porque ela necessita de apoio emocional dos pais e técnico dos professores e demais profissionais envolvidos, a fim de continuar sua vida escolar sem que a dislexia seja um empecilho para o seu desenvolvimento (SOUZA, 2011). Ainda, conforme Salles, Parente e Machado (2004), escola e família têm funções centrais na identificação precoce das dificuldades. Carvalhais e Silva (2007), em seu estudo com professores, igualmente pontuaram a necessidade de uma avaliação da dislexia efetuada precocemente, o que permite uma intervenção apropriada para combater o fracasso escolar.

Também foi encontrada uma relação significativa $\left(\chi^{2}=11,48 ; p<0,05\right)$ entre os semestres iniciantes e concluintes em relação à percepção sobre sua capacidade de diagnosticar uma pessoa com dislexia, como pode ser observado na Figura 3.

Figura 3: Relação sobre a percepção dos alunos iniciantes e concluintes sobre a sua capacidade de diagnosticar uma pessoa com dislexia $\left(\chi^{2}=11,48 ; p<0,05\right)$ 


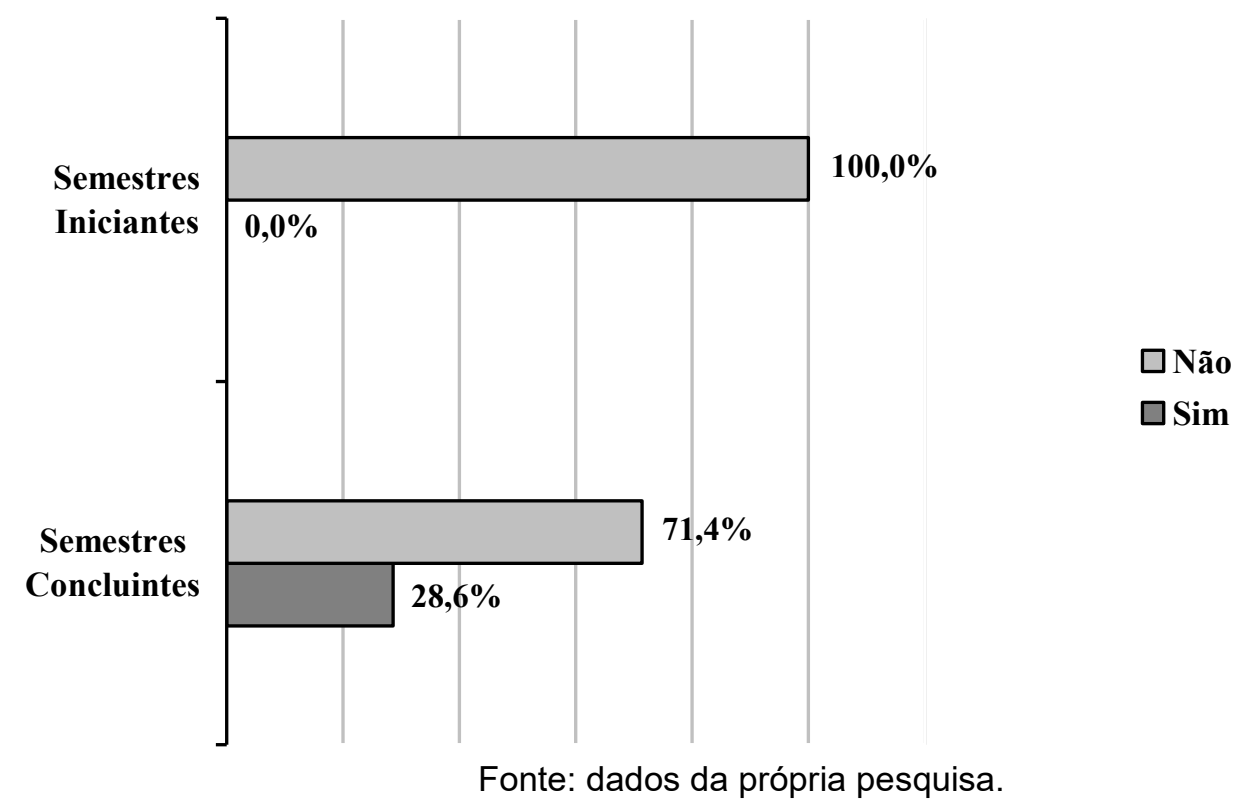

Observa-se na Figura 3 que todos os alunos iniciantes relataram que não se consideravam capacitados a diagnosticar uma pessoa com dislexia. Enquanto que entre os alunos concluintes, $71,4 \%$ não se consideravam capacitados, ou seja, em comparação, os alunos dos semestres concluintes se percebiam mais capacitados para diagnosticar uma pessoa com dislexia. Entretanto, cabe ressaltar o resultado de que apenas $28,6 \%$ dos alunos que estavam prestes a se formar se consideravam capacitados para realizar este diagnóstico. Este é um dado importante, pois a Psicologia serve como referência para avaliar e diagnosticar os problemas de aprendizagem, contribuindo para estratégias de intervenção eficientes (SALLES; PARENTE; MACHADO, 2004). Ainda, o diagnóstico precoce é imprescindível para diminuir e amenizar as implicações advindas do transtorno, favorecendo as condições de aprendizagem do indivíduo (CARVALHAIS; SILVA, 2007, RODRIGUES; CIASCA, 2016).

\subsection{PERCEPÇÃO ACERCA DO NÍVEL DE CONHECIMENTO SOBRE O TEMA DISLEXIA}

Referente à percepção dos participantes sobre seu nível de conhecimento do tema dislexia, o teste Qui Quadrado considerou que a diferença entre os semestres iniciantes e concluintes não é significativa $(p>0,05)$. Portanto, será feita uma análise 
Atos de Pesquisa em Educação - ISSN 1809-0354

Blumenau, v.14, n.2, p.431-456, mai./ago. 2019

DOI: http://dx.doi.org/10.7867/1809-0354.2019v14n2p431-456

descritiva de porcentagens, como pode ser observado na Figura 4.

Figura 4: Percepção referente ao nível de conhecimento sobre a dislexia

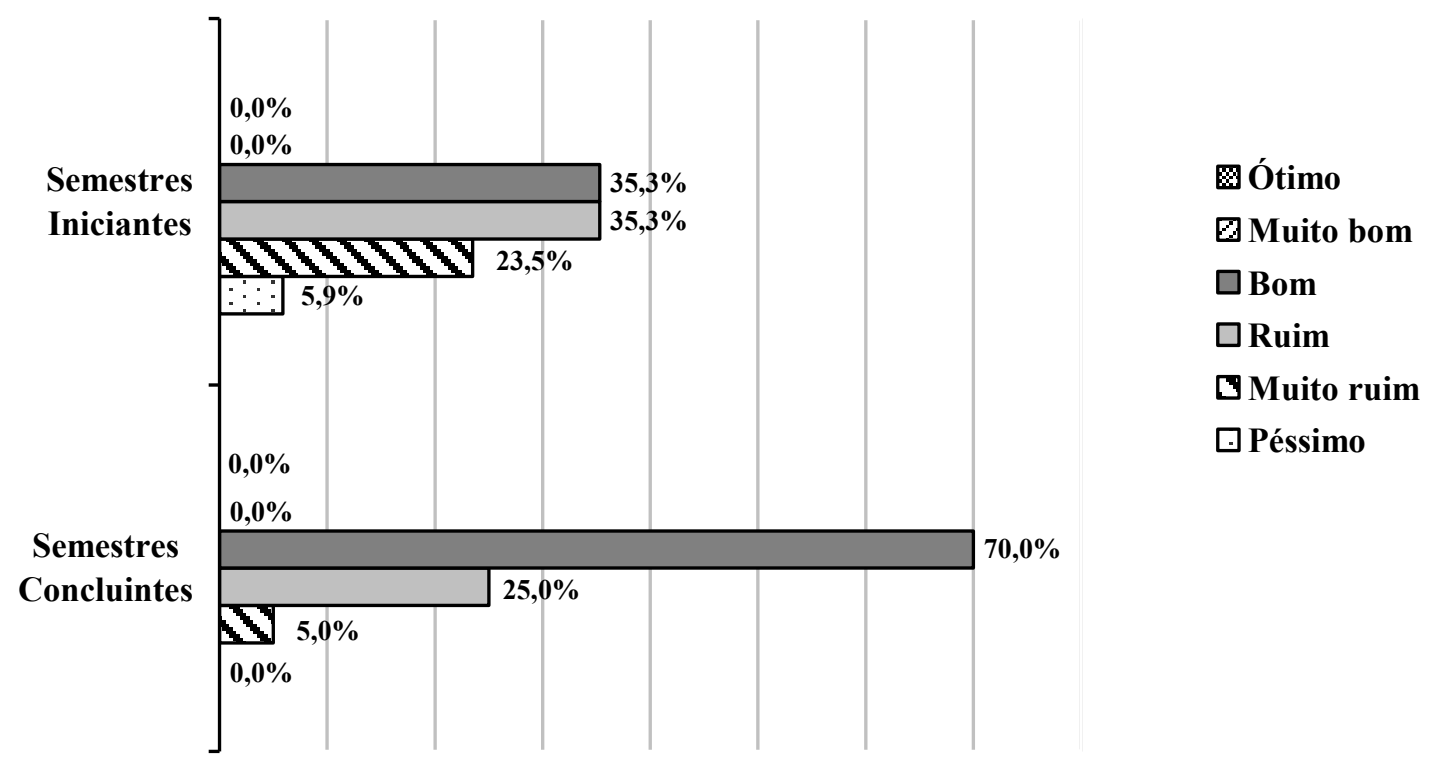

Fonte: dados da própria pesquisa.

A Figura 4 mostra que a maioria $(70,0 \%)$ dos alunos concluintes consideravam seu conhecimento como "bom". Entre os alunos iniciantes, 35,3\% avaliaram seu conhecimento como "bom" e 35,3\% consideraram "ruim". Pode-se pontuar ainda que apenas nos semestres iniciantes houve menções ao conhecimento como "péssimo" e também não houve nenhuma menção avaliando o conhecimento como "ótimo" e "muito bom", nem mesmo nos semestres concluintes.

Carvalhais e Silva (2007) concluíram em sua pesquisa que é fundamental alertar professores e profissionais da educação sobre a dislexia como dificuldade de aprendizagem, para evitar a discriminação que pode ocorrer quando não se tem conhecimento sobre o transtorno. Ainda, Stern (2010) sugere que os alunos com dislexia são mais suscetíveis a sofrerem bullying e enfrentarem problemas com os sistemas avaliativos e, por esses fatores, podem não obter progresso na área escolar. Portanto, percebe-se a importância de os profissionais que atuam na área da educação conhecerem a dislexia, para que possam trabalhar de forma significativa com o aluno com o transtorno, além de evitar que ele sofra discriminação e seja rotulado pelos colegas. 


\subsection{PERCEPÇÃO SOBRE A PESSOA COM DISLEXIA}

Para acessar a percepção dos participantes, Ihes foi pedido que citassem três palavras que descrevessem a pessoa com dislexia. Após a análise semântica das respostas e agrupamento por significação, emergiu o total de nove categorias, apresentadas na Tabela 2.

Tabela 2: Categorização das palavras mencionadas pelos participantes relacionadas à sua percepção sobre a pessoa com dislexia

\begin{tabular}{lcc}
\hline Categorias & $\boldsymbol{f}$ & $\mathbf{\%}$ \\
\hline Dislexia como problema na aprendizagem & 50 & $42,4 \%$ \\
Dislexia como problema na atenção & 19 & $16,1 \%$ \\
Possibilidades na dislexia & 14 & $11,9 \%$ \\
Dificuldade de convivência social & 10 & $8,5 \%$ \\
Consequências emocionais & 7 & $5,9 \%$ \\
Dislexia como problema de inversões de letras & 6 & $5,1 \%$ \\
Dislexia como agitação & 5 & $4,2 \%$ \\
Dislexia como problema na linguagem & 4 & $3,4 \%$ \\
Dislexia como Psicopatologia & 3 & $2,5 \%$ \\
\hline Total & $\mathbf{1 1 8}$ & $\mathbf{1 0 0} \%$ \\
\hline
\end{tabular}

Nota: $f=$ número de respostas, não de participantes.

Fonte: dados da própria pesquisa.

Conforme apresentado na Tabela 2, a categoria "dislexia como problema na aprendizagem" aparece em primeiro lugar, representando $42,4 \%$ das respostas. Nesta categoria entraram termos como: dificuldade, dificuldade no aprendizado, dificuldade na leitura, dificuldade na escrita, dificuldade da fala, falta de aprendizagem, incompreensão, lentidão e demora na aprendizagem. Este resultado concorda com o posicionamento da ABD (2016) sobre a dislexia trazer comprometimento ao aprendizado nas áreas da leitura, escrita e soletração.

Em segundo lugar está a categoria "dislexia como problema na atenção", com 16,1\% das menções. Nesta categoria encontram-se termos como: atenção, falta de atenção, desatenta, distração, concentração, desconcentrado, desatenção, distante e pouca atenção. Assunção (2018) esclarece que a dislexia não é decorrente de distração, falta de interesse ou baixa inteligência. $\mathrm{Na}$ dislexia os indivíduos apresentam, no mínimo, inteligência média (PIMENTA, 2012). Ainda, de acordo com Rodrigues (2012), alunos disléxicos são rotulados de preguiçosos ou distraídos, 
entretanto, o que eles precisam é de acolhimento e auxílio de métodos adequados para que possam superar suas dificuldades.

Na categoria "possibilidades na dislexia", com 11,9\% das respostas referidas pelos participantes, estão as menções referentes aos aspectos positivos no desenvolvimento do disléxico. Estas representações transpõem as dificuldades do transtorno e ressaltam a resiliência da pessoa com dislexia. Nesta categoria entraram termos como: desafio, criatividade, habilidade e objetivo. Conforme Souza (2011), os disléxicos podem apresentar desenvolvimento superior em áreas relacionadas à criatividade, esporte, música, entre outras. Há, inclusive, casos de superdotação concomitantes com a dislexia (TAUCEI; STOLTZ; GABARDO, 2013).

Na categoria "dificuldade de convivência social", com $8,5 \%$ das respostas dos participantes, estão descritas as dificuldades de comunicação e relacionamento, que geram consequências negativas para a vida do disléxico. Nesta categoria entraram termos como: isolamento, exclusão, convívio social, largado e diferente. A pesquisa de Mangas e Sánchez (2010) com estudantes disléxicos do Ensino Superior mostrou a existência de dificuldade de constituir relações.

Na categoria "consequências emocionais", com 5,9\% das respostas, estão as menções referentes a respostas emocionais negativas vivenciadas em decorrência do transtorno. Nesta categoria foram inclusos termos como: angústia, vergonha, constrangimento, insegura, triste e ansiosa. As consequências emocionais vivenciadas pelas pessoas com dislexia acabam impactando no seu desempenho acadêmico (APA, 2014; CABUSSÚ, 2009; SAKO, 2016; STAGG; EATON; SJOBLOM, 2018; VÁZQUEZ et al., 2017) e dificultando suas relações sociais (CABUSSÚ, 2009; MANGAS; SÁNCHEZ, 2010; STERN, 2010).

Estes aspectos podem ser percebidos na pesquisa de Mangas e Sánchez (2010) que apontou em seus resultados, em relação às consequências emocionais, que a dislexia trouxe muitos constrangimentos para a vida pessoal dos alunos entrevistados, que relataram sentirem-se inseguros, humilhados, frustrados, envergonhados e com medo de enfrentar suas disfunções.

A categoria "dislexia como problema de inversões de letras" representa $5,1 \%$ das respostas, nela entraram menções como: trocas, embaralhamento, letras embaralhadas e identifica esquerda por direita. Com 4,2\% está a categoria "dislexia 
como problemas de agitação, que traz uma conotação de hiperatividade, com palavras como: agitado e inquietude. Na categoria "dislexia como problema na linguagem", com $3,4 \%$, entraram menções como: problemas na dicção e gagueira. Por fim, na categoria "dislexia como psicopatologia", com o percentual mais baixo de 2,5\%, entraram palavras que associam dislexia a diagnósticos, como: distúrbio e transtorno.

Pode-se observar que as características que emergiram com mais frequência na fala dos participantes sobre uma pessoa com dislexia foram "problemas de aprendizagem" e "problemas na atenção", ambas com conotações negativas. Porém, a categoria "possibilidades da dislexia", terceiro lugar em menções, traz conotações positivas em relação à pessoa com o transtorno. É importante destacar que a categoria "dislexia como problema na atenção" reproduz uma ideia errada, visto que a dislexia não tem relação com falta de atenção ou distração. Porém, das 19 palavras elencadas nesta categoria, 15 foram citadas pelos alunos iniciantes e quatro, pelos concluintes.

\subsection{CONHECIMENTO DOS PARTICIPANTES SOBRE DISLEXIA}

No instrumento utilizado nesta pesquisa constavam dez questões que investigavam o conhecimento dos participantes sobre $\mathrm{o}$ transtorno (teste de conhecimento). Destas, uma tratava da definição do tema dislexia; uma, da origem do transtorno; e as outras oito, de crenças e mitos relacionados à dislexia, relatados por Teles (2004). Todas as questões eram fechadas, nove apresentavam os itens de resposta "verdadeiro" e "falso" e uma apresentava quatro itens de múltipla escolha. As questões foram corrigidas manualmente, sendo atribuídas notas (1 a 10) para o teste. Por meio destas notas foram obtidas as médias dos semestres.

$O$ teste $t$ de Student de comparação de médias do total do teste de conhecimento não apresentou diferença significativa $(p>0,05)$ entre os semestres iniciantes e concluintes em relação ao conhecimento dos alunos sobre dislexia. $\mathrm{Ou}$ seja, alunos iniciantes e concluintes de Psicologia apresentaram níveis similares de conhecimento sobre o tema. O teste de comparação de médias também não apresentou diferença significativa $(p>0,05)$ entre os sexos.

O trabalho do psicólogo em relação às dificuldades de aprendizagem é 
importante porque a sua atuação junto a estudantes com dislexia envolve medir as capacidades individuais dos alunos e estimular as suas habilidades em fatores que os comprometem no cotidiano (BRAGA, 2011). Também Carvalhais e Silva (2007), em seu estudo realizado com uma criança do quarto ano e seu Encarregado de Educação, relataram que a criança não tinha o costume de conversar com os seus pais e, por isso, considerou-se importante o apoio da psicóloga, uma vez que com ela a criança conseguiu fazer desenhos, jogos e trabalhar a leitura e a escrita.

Conforme apresentado anteriormente nas Figuras 2 e 3, o teste Qui Quadrado em relação à percepção sobre a capacidade de identificar e diagnosticar o aluno com dislexia apontou que os estudantes dos semestres concluintes se consideraram mais capazes de identificar e diagnosticar o aluno disléxico do que os iniciantes. Entretanto, em relação ao seu conhecimento, o teste apontou que essa diferença não ocorria de fato, pois os resultados obtidos foram similares, sendo a média dos estudantes iniciantes 7,53 e a dos concluintes, 7,85.

Ainda, observou-se que, em relação à percepção quanto ao nível de conhecimento sobre dislexia, $48,1 \%$ do total de alunos e $70 \%$ dos alunos concluintes consideraram seu conhecimento como bom (Figura 4). Assim, sugere-se coerente considerar que a percepção dos alunos sobre o que seria um "bom conhecimento sobre o tema" é permeada por questões subjetivas, uma vez que alunos iniciantes e concluintes obtiveram média acima de sete no teste de conhecimento.

\subsection{TESTE DE CONHECIMENTO: MÉDIA DE ERROS POR ITENS}

A Tabela 3 refere-se aos itens utilizados no teste de conhecimento, apresentando a frequência e a porcentagem de erros dos participantes, acerca do tema dislexia. Destes itens, um trata da definição do tema dislexia; um, da origem do transtorno; e os outros oito, de mitos elencados por Teles (2004).

Tabela 3: Relação de erros sobre itens do teste de conhecimento do tema dislexia

\begin{tabular}{clcc}
\hline Itens & $\boldsymbol{F}$ & $\%$ \\
\hline 1. & Dislexia e orientação espacial & 30 & $54,5 \%$ \\
2. & Dislexia e dificuldade visual & 21 & $38,2 \%$ \\
3. & Diagnóstico precoce & 16 & $29,1 \%$ \\
4. & Dislexia e cura & 15 & $27,3 \%$ \\
5. & Definição de dislexia & 13 & $26,3 \%$
\end{tabular}


6. Origem da dislexia

7. Métodos de diagnóstico

8. Diagnóstico e rotulação

9. Dislexia e reprovação

10. Dislexia em outras línguas

Fonte: dados da própria pesquisa.

Conforme se vê na Tabela 3, o item "dislexia e orientação espacial" teve a maior porcentagem de erros (54,5\%). O item usado no teste foi "a dislexia é causada por problemas de orientação espacial (lateralidade, identificação direita e esquerda, psicomotoras e grafomotoras)". Esta afirmação é falsa, pois as dificuldades espaciais são independentes da dislexia (TELES, 2004). Conforme Ferreira (2011), além das dificuldades em leitura, escrita e soletração, o transtorno envolve problemas com a linguagem expressiva, receptiva, social e corporal e cálculos matemáticos.

"Dislexia e dificuldade visual" apresentou $38,2 \%$ de erros. O item apresentado no teste foi "a dislexia não é um problema visual, a inversão de letras que ocorre são erros de origem fonológica". Esta afirmação é verdadeira, pois ocorre uma inversão fonológica quando há duas consoantes com o mesmo ponto de articulação, uma surda e uma sonora (TELES, 2004).

"Diagnóstico precoce" teve 29,1\% de erros. O item apresentado foi "a dislexia só pode ser diagnosticada e tratada após ser constatado o insucesso na leitura". Esta afirmação é falsa, já que as dificuldades de aprendizagem podem e devem ser diagnosticadas o mais cedo possível; pois conhecer o transtorno possibilita identificar sinais de alerta, como comprometimento na aprendizagem da linguagem oral (TELES, 2004). Ainda, conforme Carvalhais e Silva (2007) e Rodrigues e Ciasca (2016), é de grande importância o diagnóstico precoce para amenizar as consequências do transtorno.

"Dislexia e cura" obteve $27,3 \%$ de erros. O item do teste foi "a dislexia não tem cura, mantém-se ao longo da vida". A afirmação é verdadeira, a dislexia não passa com o tempo, permanecendo na vida adulta (CABUSSÚ, 2009; TELES, 2004). O trabalho de Bonini et al (2010) com um participante de 42 anos ilustra como as experiências e frustrações podem ocorrer desde a vida escolar até a adulta.

"Definição de dislexia" obteve $26,3 \%$ de erros. $O$ item apresentou quatro opções de respostas, sendo a opção verdadeira "transtorno específico da aprendizagem que compromete o aprendizado nas áreas da leitura, escrita e soletração" (ABD, 2016). $O$ 
estudo de Stern (2010) com um aluno disléxico mostrou que, dentre as principais barreiras enfrentadas no período escolar estavam problemas com a leitura, erros ortográficos, letra ilegível e dificuldades para compreender textos.

"Origem da dislexia" apresentou $21,8 \%$ de erros. O item utilizado foi "a dislexia tem origem neurobiológica". Esta afirmação é verdadeira, a dislexia tem origem neurobiológica (ABD, 2016; CABUSSÚ, 2009; INSTITUTO DE APOIO À CRIANÇA, 2011), sendo uma incapacidade específica de aprendizagem (APA, 2014; INSTITUTO DE APOIO À CRIANÇA, 2011). Ela é uma condição hereditária da linguagem, com alterações genéticas (ABD, 2016).

"Métodos de diagnóstico" teve $14,5 \%$ de erros. O item apresentado no teste foi "ainda não existem métodos para diagnosticar a dislexia, como testes e provas específicos para avaliar as diversas competências que envolvem o processo de leitura". Esta afirmação é falsa, já que atualmente existem saberes que possibilitam a avaliação e o diagnóstico de crianças disléxicas, com testes específicos para a avaliação de suas competências (TELES, 2004). Inclusive, a atuação do psicólogo se dá por meio de testes padronizados (BRAGA, 2011).

"Diagnóstico e rotulação" teve $12,7 \%$ de erros. O item do teste foi "deve-se evitar diagnosticar as crianças disléxicas, pois este rótulo contribuiria para o agravamento da dislexia". Esta afirmação é falsa. Conforme Carvalhais e Silva (2007) existe a necessidade de uma avaliação da dislexia efetuada precocemente (CARVALHAIS; SILVA, 2007; RODRIGUES; CIASCA, 2016).

"Dislexia e reprovação" apresentou $9,1 \%$ de erros. O item apresentado foi "repetir o aluno de ano o ajuda a vencer as dificuldades causadas pela dislexia". A afirmação é falsa, visto que a repetência pode acrescentar ainda mais dificuldades ao aluno, relacionadas a aspectos emocionais, como frustração e ansiedade (TELES, 2004).

"Dislexia em outras línguas" foi o item com menos erros $(1,8 \%)$. O item apresentado foi "a dislexia existe apenas em algumas línguas". A afirmação é falsa, pois a dislexia se manifesta em todas as línguas, porém em algumas pode-se cometer mais erros, relacionados às competências da leitura, do que em outras, decorrentes das diferentes ortografias (TELES, 2004).

Em conclusão, pode-se perceber que os alunos eram mais bem informados 
quanto ao fato de a dislexia se apresentar em todas as línguas, de que a repetência não traz benefícios para a vida escolar do aluno disléxico e sobre a importância do diagnóstico. Entretanto, havia menores níveis de conhecimento dos alunos sobre sua relação com problemas de lateralidade e de visão, aspectos que não são de fato relacionados à dislexia.

\section{CONSIDERAÇÕES FINAIS}

Era objetivo desta pesquisa investigar a percepção e o conhecimento sobre aspectos relacionados à dislexia em acadêmicos de Psicologia de uma faculdade do Norte de Santa Catarina. Foi possível identificar uma diferença na percepção entre os semestres, referente à capacidade de identificar e diagnosticar a pessoa com dislexia, onde os acadêmicos concluintes se perceberam mais capacitados a realizar estas ações.

Ao referir-se ao conhecimento dos alunos sobre o tema dislexia, percebeu-se que não existia diferença estatística entre as fases, já que o conhecimento apresentado por acadêmicos iniciantes e concluintes mostrou resultados semelhantes, apesar dos seus diferentes momentos de formação. Em relação às médias de erros apresentados sobre o conhecimento dos itens acerca do tema dislexia, pôde-se perceber que uma parte considerável dos alunos concordou com alguns conceitos falsos sobre a dislexia, como apontar problemas de orientação espacial como causa e relacionar o transtorno a problemas visuais.

Quanto à percepção sobre o nível de conhecimento do tema dislexia, houve uma prevalência dos semestres concluintes, cujos alunos consideraram o seu conhecimento como bom. Nesse sentido, a percepção dos estudantes de semestres concluintes sobre seu conhecimento de dislexia foi coerente com os resultados do teste de conhecimento sobre dislexia, considerando sua média. Porém, tanto aqueles dos semestres concluintes quanto os iniciantes apresentaram um bom conhecimento referente ao tema dislexia, considerando que as duas médias se situaram entre sete e oito. Sugere-se que novas pesquisas que se utilizem de testes mistos, com perguntas abertas e fechadas sobre o tema, possam contribuir mais no quesito avaliação do conhecimento sobre dislexia. Considerou-se que, por apresentar apenas 
questões fechadas, o teste de conhecimento utilizado foi uma limitação desta pesquisa.

Ainda sobre a percepção, buscou-se saber também quais as características que os participantes atribuíam a uma pessoa com dislexia e a maioria dos resultados apontou conotações negativas, como problemas de aprendizagem e de atenção, sendo este último item uma noção errada sobre o transtorno.

Conclui-se pela importância de discutir o tema com mais ênfase no curso Psicologia, no sentido de desfazer falsos entendimentos sobre o transtorno. $O$ profissional que venha a intervir, tanto com a criança, quanto com os pais, professores e colegas, deve ter conhecimento e propriedade no assunto, pois o apoio social e emocional pode evitar o sofrimento psicológico e contribuir para uma aprendizagem mais significativa e para a qualidade da saúde mental da pessoa com dislexia.

\section{LUMACHELLE LAIZ SCHÜNKE}

Psicóloga pelo Centro Universitário Leonardo Da Vinci - UNIVINCI

\section{JESIANE BORBA}

Acadêmica do Centro Universitário Leonardo Da Vinci - UNIVINCI

\section{ROSINA FORTESKI GLIDDEN}

Psicóloga, Mestra e Doutoranda em Educação pela Universidade Federal do Paraná - UFPR. Professora de Psicologia e Orientadora de Iniciação Científica do Centro Universitário Leonardo Da Vinci - UNIVINCI

\section{REFERÊNCIAS}

AMERICAN PSYCHIATRIC ASSOCIATION (APA). Manual diagnóstico e estatístico de transtornos mentais: DSM-5-TR. 5. ed. Porto Alegre: Artmed, 2014, 976 p.

ANDRADA, E. G. C. de. Focos de intervenção em psicologia escolar. Psicologia Escolar e Educacional, Campinas, v. 9, n.1, p.163-165, jun. 2005. Disponível em: $<$ http://www.scielo.br/scielo.php?script=sci arttext\&pid=S141385572005000100019>. Acesso em: 18 jul. 2017.

ASSOCIAÇÃO BRASILEIRA DE DISLEXIA (ABD). O que é dislexia. 2016. Disponível em: < http://www.dislexia.org.br/o-que-e-dislexia/ Acesso em: 18 jul. 2017.

ASSUNÇÃO, G. S. A dislexia e os desafios nos processos de aprendizagem da 
Língua Portuguesa. Monografia (Licenciatura em Língua Portuguesa e Literaturas) Universidade do Estado da Bahia, Santo Antônio de Jesus, 2018.

BONINI, F. V., et al. Problemas emocionais em um adulto com dislexia: um estudo de caso. Revista Psicopedagogia, São Paulo, v. 27, n. 83, p. 310-322, 2010. Disponível em:

<http://pepsic.bvsalud.org/scielo.php?script=sci_arttext\&pid=\$010384862010000200 016>. Acesso em: 18 jul. 2017.

BRAGA, S. G. Dislexia: a produção do diagnóstico e seus efeitos no processo de escolarização. 2011. Dissertação (Mestrado em Psicologia) - Instituto de Psicologia, Universidade de São Paulo, São Paulo.

CARVALHAIS, L. S. de A.; SILVA, C. Consequências sociais e emocionais da Dislexia de desenvolvimento: um estudo de caso. Revista Semestral da Associação Brasileira de Psicologia Escolar e Educacional (ABRAPEE), v. 11, n. 1, p. 21-29, 2007. Disponível em: <http://www.scielo.br/pdf/pee/v11n1/v11n1a03.pdf>. Acesso em: 18 jul. 2017.

CABUSSÚ, M. A. S. T. Dislexia e estresse: implicações neuropsicológicas e psicopedagógicas. Revista Psicopedagogia, v. 26, n. 81, p. 476-485, 2009. Disponível em: <http://pepsic.bvsalud.org/pdf/psicoped/v26n81/v26n81a15.pdf> Acesso em: 02 mar. 2018.

DEUSCHLE, V. P.; CECHELLA, C. O déficit da consciência fonológica e sua relação com a dislexia. Revista CEFAC, v. 11, n. 2, p. 194-200, 2009. Disponível em: <http://www.scielo.br/pdf/rcefac/v11s2/16-08>. Acesso em: 18 jul. 2017.

FERREIRA, C. S. S. Dislexia: um estudo de caso. 2011. Dissertação (Mestrado) Escola Superior de Educação de Coimbra, Coimbra.

INSTITUTO DE APOIO À CRIANÇA. Boletim do Centro de Estudos, Documentação e Informação sobre a Criança do Instituto de Apoio à Criança. InfoCEDI. n. 32, 2011. Disponível em: <

http://www.appdae.net/documentos/informativos/infocedi dislexia.pdf $>$ Acesso em: 18 ago. 2017.

MANGAS, C. F.; SÁNCHEZ, J. L. R. A dislexia no ensino superior: características, consequências e estratégias de intervenção. Revista Ibero-americana de Educação, v.7, n. 53, 2010. Disponível em: <http://rieoei.org/deloslectores/3635Frade.pdf>. Acesso em: 18 jul. 2017.

ORGANIZAÇÃO MUNDIAL DA SAÚDE. Classificação dos Transtornos Mentais e de Comportamento - CID -10. Porto Alegre: Artes Médicas, 1993, 410 p.

PEREIRA, L. V. et al. Estudo investigativo sobre o conhecimento da dislexia em educadores da rede pública e privada dos Municípios de Belo Horizonte e de Nova Lima. Revista Tecer, Belo Horizonte, v. 4, n. 6, p. 26-40, 2011. Disponível em: 
Atos de Pesquisa em Educação - ISSN 1809-0354

Blumenau, v.14, n.2, p.431-456, mai./ago. 2019

DOI: http://dx.doi.org/10.7867/1809-0354.2019v14n2p431-456

<http://www.bibliotekevirtual.org/index.php/2013-02-07-03-02-35/2013-02-07-03-0311/728-rt/v04n06/7146-estudo-investigativo-sobre-o-conhecimento-da-dislexia-emeducadores-da-rede-publica-e-privada-dos-municipios-de-belo-horizonte-e-de-novalima.html>. Acesso em: 18 jun. 2017.

PESTANA, M. H.; GAGEIRO, J. N. Análise de dados para Ciências

Sociais: a complementaridade do SPSS. 3. ed. Lisboa: Silabo, 2003, 32 p.

PIMENTA, D. C. F. G. Dislexia: um estudo sobre a percepção de professores do ensino fundamental. In: V SEMINÁRIO NACIONAL DE EDUCAÇÃO ESPECIAL E VI ENCONTRO DE PESQUISADORES EM EDUCAÇÃO ESPECIAL E INCLUSÃO ESCOLAR. 2012, Uberlândia. Anais... Uberlândia, Universidade Federal de Uberlândia, 2012. Disponível em:

<http://www.cepae.faced.ufu.br/sites/cepae.faced.ufu.br/VSeminario/trabalhos/288 1 1.pdf>. Acesso em: 18 jun. 2017.

RODRIGUES, P. C. da C. S. Intervenção educativa em alunos com Dislexia na aprendizagem das ciências naturais. 2012. Dissertação (Mestrado em Educação Especial) - Escola Superior de Educação de Coimbra, Coimbra.

RODRIGUES, S. D. R.; CIASCA, S. M. Dislexia na escola: identificação e possibilidades de intervenção. Revista Psicopedagogia, v.33, n.100, p. 86-97, 2016. Disponível em: <http://pepsic.bvsalud.org/scielo.php?script=sci arttext\&pid=S010384862016000100010>. Acesso em: 26 fev. 2018.

SAKO, E. The emotional and social effects of dyslexia. European Journal of Interdisciplinary Studies, v. 4, n. 2, p. 231-329, 2016. Disponível em:

<http://journals.euser.org/files/articles/ejis jan apr 16/Enkeleda.pdf >. Acesso em: 26 fev. 2018.

SALLES, J. F. de; PARENTE, M. A. de M. P.; MACHADO, S. da S. As dislexias de desenvolvimento: aspectos neuropsicológicos e cognitivos. Revista Interações, São Paulo, v. 9, n. 17, p. 109-132, jun. 2004. Disponível em:

<http://pepsic.bvsalud.org/scielo.php?script=sci arttext\&pid=S141329072004000100007>. Acesso em: 18 jul. 2017.

SILVA, S. S. L. Conhecendo a dislexia e a importância da equipe interdisciplinar no processo de diagnóstico. Revista Psicopedagogia, São Paulo, v.26, n.81, p.470-475, 2009. Disponível em: <

http://pepsic.bvsalud.org/scielo.php?script=sci arttext\&pid=S010384862009000300014>. Acesso em: 18 ago. 2019.

SOUZA, J. de. Dislexia em sala de aula: a função do professor. 2011. Monografia (Graduação em Pedagogia) - Universidade Estadual de Maringá, Cianorte.

STAGG, S. D.; EATON, E.; SJOBLOM, A. M. Self-efficacy in undergraduate students with dyslexia: a mixed methods investigation. British Journal of Special Education, v. 45, n. 1, p. 26-42, 2018. Disponível em: 
$<$ http://onlinelibrary.wiley.com/doi/10.1111/1467-8578.12200/abstract>. Acesso em: 18 jul. 2017.

STERN, A. C. B. As barreiras encontradas pelo disléxico no ensino regular. 2010. Monografia (Graduação) - Centro de Ciências Biológicas e da Saúde, Universidade Presbiteriana Mackenzie, São Paulo.

TAUCEI, J. R.; STOLTZ, T.; GABARDO, C. V. Caminhos e descaminhos: a trajetória complexa do aluno com AH/SD e Dislexia na escola. Cadernos de Educação, Pelotas, n. 44, p. 265-292, jan./abr. 2013. Disponível em: $<$ https://periodicos.ufpel.edu.br/ojs2/index.php/caduc/article/view/2748/2500>. Acesso em: 18 jul. 2017.

TELES, P. Dislexia: Como identificar? Como intervir?. Revista Porto Clínica Geral, v. 20, n. 1, p.713-730, Lisboa, 2004. Disponível em:

$<$ http://www.aevagos.edu.pt/pluginfile.php/1718/mod resource/content/1/Dislexia.pdf >. Acesso em: 18 jul. 2017.

VÁZQUEZ, A. J. S. et al. La dislexia, la disgrafia y la discalculia: sus consecuencias en la educación ecuatoriana. Revista Archivo Médico de Camagüey, v.21, n.1, p. 766-772, 2017.

VERAS, F. de C. A dislexia e a linguagem com foco na leitura e produção textual. 2013. Monografia (Graduação em Língua Portuguesa) - Instituto de Letras.

Universidade de Brasília, Brasília. 